\title{
Effect of Drying Temperature on Sensory Properties of Mustard Flour (Brassica juncea) Using Oven Dryer
}

\section{Pengaruh Suhu Pengeringan Terhadap Sifat Sensori Tepung Sawi (Brassica juncea) Menggunakan Pengering Oven}

\author{
Yeny Ekawati ${ }^{1}$, Ida Agustini Saidi ${ }^{2}$ \\ \{yeny.ekawati@yahoo.co.id ${ }^{1}$, idasaidi@yahoo.com ${ }^{3}$ \}
}

Universitas Muhammadiyah Sidoarjo

\begin{abstract}
This study aims to determine the effect of drying temperatures on sensori properties of mustard greens flour. The study was conducted from February to April 2020. Hedonic test used non-parametric statistical to determine sensori properties of mustard greens flour.The sample used was mustard greens (Brassica juncea) from Waru, Sidoarjo. Various temperature used oven drying at $40^{\circ} \mathrm{C}, 50^{\circ} \mathrm{C}, 60^{\circ} \mathrm{C}$ and $70^{\circ} \mathrm{C}$. The results showed that the drying temperatures has not difference on hedonic test of color, aroma, and texture of mustard flour.
\end{abstract}

Keywords - Drying Temperature; Mustard Greens Flour

Abstrak. Penelitian ini bertujuan untuk mengetahui pengaruh berbagai suhu terhadap karakteristik organoleptik tepung sawi. Penelitian dilaksanakan mulai bulan Februari sampai dengan bulan April 2020. Sifat sensoris tepung sawi menggunakan hedonic tes dan analisis statistik non parametrik. Sampel yang digunakan adalah sawi hijau (Brassica juncea) yang diperoleh dari pasar Waru, Sidoarjo yang akan dibua ttepung sawi dengan cara dikeringkan menggunakan pengering oven pada suhu $40^{\circ} \mathrm{C}, 50^{\circ} \mathrm{C}, 60^{\circ} \mathrm{C}$, dan $70^{\circ} \mathrm{C}$. Hasil penelitian menunjukkan tidak terdapat perbedaan yang nyata terhadap sifat sensori meliputi warna, aroma, dan tekstur dari tepung sawi.

Kata Kunci-Suhu Pengeringan; Tepung Sawi

\section{Pendahuluan}

Sawi merupakan komoditas sayuran yang penting di Indonesia dan tidak dapat dipisahkan dari kebutuhan seharihari di dalam konsumsi rumah tangga tanpa memperhatikan tingkat sosial. Ada beberapa jenis sawi yaitu sawi putih (Brassica pekinensis) disebut juga petsai, sawi hijau (B. juncea) atau disebut juga sawi bakso, kalian (B. oleracea), dan sawi sendok (B. chinensis) atau disebut juga pok coy. Selain memiliki keragaman jenis, sawi juga memiliki kandungan gizi yang cukup tinggi [1].

Sawi banyak digemari oleh masyarakat karena rasanya enak dan mudah didapat, akan tetapi salah satu sifat sayuran termasuk sawi adalah cepat layu dan busuk akibat kurang cermatnya penanganan paska panen. Untuk memperpanjang masa simpannya dapat dilakukan dengan berbagai pengolahan, misalnya kerupuk, mie, tepung, dan lain-lain. Tepung adalah produk awetan yang diperoleh dari proses penggilingan suatu bahan dalam bentuk butiranbutiran halus dengan kadar air 10-13\% [2].

Pada umumnya tepung diolah dari bahan dengan kandungan karbohidrat atau pati yang tinggi. Disamping untuk mempertahankan umur simpan bahan, pengolahan tepung sangat mudah untuk dilakukan, oleh karena itu banyak dikembangkan olahan tepung dari berbagai bahan baku misalnya tepung pandan [2]; tepung formula tempe [3]; tepung sayuran [4]; tepung biji alpukat [5] dan lain sebagainya.

Sawi memiliki kadar air yang cukup tinggi hingga 92,2 \% [6], untuk mengubah sawi menjadi tepung sawi adalah dengan cara pengeringan. Pengeringan didefinisikan sebagai proses pengeluaran atau pemisahan air dari suatu bahan menggunakan panas. Metode pengeringan yang umum digunakan adalah peneringan matahari atau penjemuran. Namun metode ini merupakan metode pengeringan yang lambat karena sangat tergantung pada cuaca. Selain itu, selama proses penjemuran dapat terjadi kontaminai oleh debu, kotoran ataupun serangga [7].

Suhu pengeringan merupakan faktor penting untuk menghasilkan produk dengan mutu yang baik. Berdasarkan hasil penelitian pendahuluan, suhu optimum pengeringan sawi menggunakan pengering oven yaitu pada suhu $40{ }^{\circ} \mathrm{C}$ hingga suhu $70^{\circ} \mathrm{C}$. Secara umum, semakin besar perbedaan suhu antara medium pemanas dengan bahan pangan maka akan mempercepat proses pindah panas ke bahan sehingga penguapan air dari bahan pangan akan semakin cepat dan bahan menjadi lebih cepat kering. Sehingga dapat disimpulkan bahwa suhu pengeringan berbanding terbalik dengan waktu pengeringan. Pada pengeringan dengan suhu yang rendah, waktu pengeringan akan berlangsung lama, sedangkan pada suhu tinggi, proses pengeringan akan lebih cepat [7]. Oleh karena itu dilakukan penelitian untuk mengetahui sifat sensori Tepung sawi pada berbagai suhu pengeringan. 
Procedia of Engineering and Life Science Vol. 1. No. 2 Juni 2021

Seminar Nasional \& Call Paper Fakultas Sains dan Teknologi (SENASAINS 2nd)

Universitas Muhammadiyah Sidoarjo

\section{METODE}

Penelitian dilaksanakan pada bulan Februari sampai dengan bulan April 2020. Sampel yang digunakan adalah sawi hijau (Brassica juncea) yang diperoleh dari pasar Kejapanan, Gempol-Pasuruan yang akan dibuat tepung sawi dengan cara dikeringkan menggunakan pengering oven pada suhu $40^{\circ} \mathrm{C}, 50^{\circ} \mathrm{C}, 60{ }^{\circ} \mathrm{C}$ dan $70^{\circ} \mathrm{C}$. Alat yang digunakandalampenelitianiniadalahtimbangan digital merk Ohaus, loyang, oven, pisau, telenan, blender, ayakan, dan baskom. Sedangkan bahan yang digunakan dalam pembuatan Tepung sawi adalah sawi hijau dan aquades. Diagram alir pembuatan tepung sawi disajikan pada Gambar 1.

Prosedur pembuatan tepung sawi modifikasi Lubis dengan menggunakan sawi sebagai bahan baku [2]. Tahapan pembuatan tepung sawi dimulai dengan sawi dipisahkan dari bagian akar dan batang serta bagian yang rusak dan dicuci dengan air mengalir, kemudian ditiriskan. Potong-potong dengan ukuran kurang lebih $2 \mathrm{~cm}$, timbang masingmasing $300 \mathrm{~g}$ untuk tiap perlakuan. Atur dalam loyang, kemudian keringkan dengan pengering oven pada suhu sesuai perlakuan $\left(40{ }^{\circ} \mathrm{C}, 50{ }^{\circ} \mathrm{C}, 60^{\circ} \mathrm{C}\right.$, dan $\left.70{ }^{\circ} \mathrm{C}\right)$ hingga kering. Blender sawi yang telah kering hingga halus, kemudian ayak dengan ayakan 80 mesh.

Penentuan sifat sensori dengan hedonic test meliputi warna, aroma, dan tekstur tepung sawi. Panelis test menggunakan uji hedonik dan hasilnya dinyatakan dalam angka 1 - 5. 30 orang panelis diminta untuk menilai sample berdasarkan atas kesukaan dan ketidak sukaan panelis akan sampel tersebut dengan memberikan nilai yang sesuai.

\section{Hasil dan Pembahasan}

\section{A. Pengeringan sawi}

Hasil pengeringan sawi menggunakan pengering oven dengan variasi suhu $40{ }^{\circ} \mathrm{C}, 50{ }^{\circ} \mathrm{C}, 60{ }^{\circ} \mathrm{C}$ dan $70{ }^{\circ} \mathrm{C}$, sampel yang digunakan adalah bagian daun sawi. Pengeringan dilakukan sampai sawi kering dengan ciri-ciri apabila daun sawi diremas menggunakan tangan mudah hancur. Waktu yang dibutuhkan masing-masing suhu untuk mengeringkan daun sawi berturut-turut 10 jam 13 menit, 7 jam 15 menit, 6 jam 7 menit, dan 5 jam 34 menit. Semakin tinggi suhu pengeringan, maka semakin pendek pula waktu yang dibutuhkan.

\section{B. Sifat sensori tepung}

Sifat sensori tepung sawi dapat dilihat pada Tabel 1. Tingkat kesukaan panelis terhadap warna tepung sawi berkisar antara 3,20-3,47 (biasa-suka). Tingkat kesukaan tertinggi pada perlakuan suhu pengeringan $50^{\circ} \mathrm{C}$ yang menunjukkan nilai 3,47 (biasa-suka) meskipun berbeda tidak nyata dengan perlakuan yang lainnya. Panelis lebih menyukai tepung sawi dengan warna hijau cerah (Gambar 1).

Tabel 1. Sifat Sensori Tepung Sawi

\begin{tabular}{clccc}
\hline \multirow{2}{*}{ No } & \multicolumn{1}{c}{ Perlakuan } & \multicolumn{3}{c}{ Rerata Sifat Sensori } \\
\cline { 3 - 5 } & & Warna & Aroma & Tekstur \\
\hline 1 & Suhu $40^{\circ} \mathrm{C}$ & 3,20 & 3,10 & 3,37 \\
2 & Suhu $50^{\circ} \mathrm{C}$ & 3,47 & 3,57 & 3,10 \\
3 & Suhu 60 oC & 3,33 & 3,13 & 3,10 \\
4 & Suhu 70 $70^{\circ}$ & 3,33 & 3,23 & 3,57 \\
\hline
\end{tabular}

Tingkat kesukaan panelis terhadap aroma tepung sawi berkisar antara 3,10-3,57 (biasa-suka). Tingkat kesukaan tertinggi pada perlakuan suhu pengeringan $50^{\circ} \mathrm{C}$ yang menunjukkan nilai 3,57 (biasa-suka) meskipun berbeda tidak nyata dengan perlakuan yang lainnya. Pada suhu pengeringan $40^{\circ} \mathrm{C}$ panelis menilai aroma langu sawi terlalu kuat, sehingga panelis memberikan nilai terendah.

Aroma lebih banyak berhubungan dengan panca indera pembau. Pada umumnya bau yang diterima oleh hidung dan otak lebih banyak merupakan campuran empat bau utama yaitu aroma, asam, tengik dan hangus [8].

Tingkat kesukaan panelis terhadap tekstur tepung sawi berkisar antara 3,10-3,57 (biasa-suka). Tingkat kesukaan tertinggi pada perlakuan suhu pengeringan $70^{\circ} \mathrm{C}$ yang menunjukkan nilai 3,57 (biasa-suka) meskipun berbeda tidak nyata dengan perlakuan yang lainnya.

Tekstur merupakan sekelompok sifat fisik yang ditimbulkan oleh elemen struktural bahan pangan yang dapat dirasa oleh indera peraba [9]. Tekstur tepung dipengaruhi oleh kadar airnya, sedangkan kadar air tepung dipengaruhi oleh suhu/temperatur dan lama pengeringan [10]; [11]. 
Procedia of Engineering and Life Science Vol. 1. No. 2 Juni 2021

Seminar Nasional \& Call Paper Fakultas Sains dan Teknologi (SENASAINS 2nd)

Universitas Muhammadiyah Sidoarjo

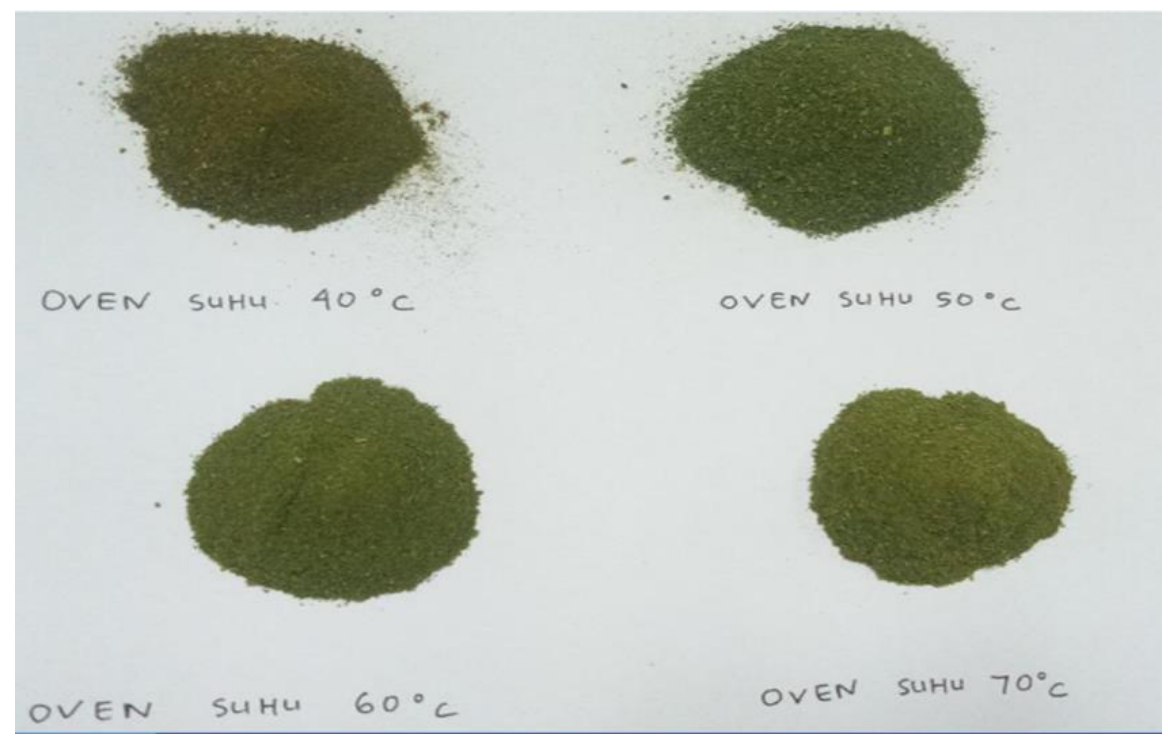

Gambar 1. Warna Tepung Sawi pada Berbagai Suhu Pengeringan

\section{Perlakuan terbaik}

Perhitungan mencari perlakuan terbaik tepung sawi ditentukan berdasarkan perhitungan nilai efektifitas melalui prosedur pembobotan. Hasil yang diperoleh dengan mengalikannya dengan data rata-rata hasil analisis uji organoleptic terhadap aroma, warna, tekstur pada setiap perlakuan (Tabel 2).

Hasil perhitungan perlakuan terbaik adalah tepung sawi dengan perlakuan pengeringan $50^{\circ} \mathrm{C}$ yang memberikan nilai normal 0,51 dengan karakteristik organoleptik tekstur 3,10 (netral-suka), organoleptik warna 3,47 (netral-suka), dan organoleptik aroma 3,57 (netral-suka).

Tabel 2. Nilai Efektifitas Masing-masing Perlakuan Berdasarkan Hasil Perhitungan Mencari Perlakuan Terbaik

\begin{tabular}{|c|c|c|c|c|c|}
\hline \multirow{2}{*}{ No } & \multirow{2}{*}{ Parameter } & \multicolumn{4}{|c|}{ Perlakuan } \\
\hline & & Suhu $40^{\circ} \mathrm{C}$ & Suhu $50^{\circ} \mathrm{C}$ & Suhu $60^{\circ} \mathrm{C}$ & $\mathrm{Suhu}^{\circ 0^{\circ} \mathrm{C}}$ \\
\hline 1 & Organoleptik warna & 3,20 & 3,47 & 3,33 & 3,33 \\
\hline 2 & Organoleptik tekstur & 3,10 & 3,57 & 3,13 & 3,23 \\
\hline 3 & Organoleptik aroma & 3,37 & 3,10 & 3,10 & 3,57 \\
\hline & Nilai Efektifitas & 0,36 & $0,51 *$ & 0,45 & 0,47 \\
\hline
\end{tabular}

Keterangan: *perlakuan terbaik

\section{KESIMPULAN}

Selama proses pengeringan semakin besar perbedaan suhu antara medium pemanas dengan bahan pangan, maka akan mempercepat proses pindah panas kebahan sehingga penguapan air dari bahan pangan akan semakin cepat dan bahan menjadi lebih cepat kering. Sehingga dapat disimpulkan bahwa suhu pengeringan berbanding terbalik dengan waktu pengeringan. Pada pengeringan dengan suhu yang rendah, waktu pengeringan akan berlangsung lama, sedangkan pada suhu tinggi, proses pengeringan akan lebih cepat. Secara statistik suhu pengeringan tidak berpengaruh nyata terhadap sifat sensori tepung sawi. Hasil perhitungan perlakuan terbaik adalah tepung sawi dengan perlakuan suhu pengeringan $50^{\circ} \mathrm{C}$ yang memberikan nilai normal 0,51 dengan karakteristik organoleptik tekstur 3,10 (netral-suka), organoleptik warna 3,47 (netral-suka), dan organoleptik aroma 3,57 (netral-suka).

\section{REFERENSI}

[1] Z. Sangaji, "Kajian Sistem Budidaya Tanaman Sawi (Brassica juncea L) di Oetani Kelurahan Malawele Distrik Aimas Kabupaten Sorong," vol. IX, no. 1, 2017.

[2] I. H. Lubis, "Pengaruh Lama dan Suhu Pengeringan Terhadap Mutu Tepung Pandan," Universitas Sumatera 
Utara, Sumatera Utara, 2008.

[3] A. N. Oktavia, "Studi Pembuatan Tepung Formula Tempe.," Universitas Hasanuddin, Makassar, 2012.

[4] Muhtadi, R. Rauf, K. Harismah and Saifuddin, "Pengembangan Produk Olahan Tepung Sayuran di Desa Sindon Kecamata n Ngemplak Kabupaten Boyolali," vol. XIX, no. 1, 2016.

[5] W. T. Jayanti, "Substitusi tepung terigu dengan Tepung Biji Alpukat terhadap Sifat Fisik Cookies," Universitas Diponrgoro, Semarang, 2017.

[6] I. P. K. Jaya, "Mempelajari Karakter Pengeringan Sawi Hijau (Brassica rapa var parachinensis," Universitas Lampung, Bandar Lampung, 2018.

[7] K. Ahmadi and T. Estiasih, Teknologi Pengolahan Pangan, Jakarta: Bumi Aksara, 2009.

[8] A. S. Dyah, "Pengaruh Berbagai Perlakuan Pendahuluan Terhadap Kualitas Tepung Sawi Hijau (Brassica juncea) yang Dikeringkan dengan Pengering Kabinet," Universitas Muhammadiyah Sidoarjo, Sidoarjo, 2021.

[9] A. I. Faradela, "Pengaruh Konsentrasi Kalsium Klorida (CaCl2) dan Penggunaan Edible Coating Terhadap Karakteristik Friench Fries Kimpul (Xanthosoma sagittifolium)," Universitas Muhammadiyah Sidoarjo, Sidoarjo, 2017.

[10] Y. H. Diza, T. Wahyuningsih and Silfia, "Penentuan Waktu dan Suhu Pengeringan Optimal terhadap Sifat Fisik Bahan Pengisi Bubur Kampiun Instan Menggunkakan Pengering Vakum," vol. iv, no. 2, 2014.

[11] E. Sinurat and Murniyati, "Pengaruh Waktu dan Suhu Pengeringan terhadap Kualitas Permen Jeli," vol. ix, no. 2, 2014. 